Brit. J. prev. soc. Med. (1975), 29, 27-30

\title{
Some sources of stress found in mothers of spina bifida children
}

\author{
BRIAN TEW AND K. M. LAURENCE \\ Department of Child Health, Welsh National School of Medicine, Heath Park, Cardiff
}

\begin{abstract}
Tew, B. and Laurence, K. M. (1975). British Journal of Preventive and Social Medicine, 29, 27-30. Some sources of stress found in mothers of spina bifida children. The scores on a malaise inventory for 51 mothers of spina bifida children born between 1956 and 1962 in South Wales revealed significantly higher scores when the child was incontinent, had a severe locomotor disability, had an IQ less than 80 , and was attending a special school rather than a normal school. No difference in scores was found between the sexes or for size of family, and only a slight difference occurred between the malaise scores of mothers of mildly and moderately handicapped children.
\end{abstract}

The introduction in the early 1960 s of an active surgical policy for the treatment of children born with spina bifida cystica has produced a considerable increase in the number of survivors reaching school age. A number of workers have investigated the effect that a spina bifida child can have on the family and have concluded that, more often than not, this is a stressful experience for parents and siblings. This information has been collected either through interviewing parents (Hare et al., 1966; D'Arcy, 1968; Freeston, 1971; Walker, Thomas, and Russell, 1971; Hunt, 1973) or from standardized questionnaires (Hare et al., 1972; Tew and Laurence, 1973). We here report the results obtained from a questionnaire known as the 'malaise inventory' (Rutter et al., 1970) which was completed in 1971 by parents of children born with spina bifida cystica in South Wales between 1956 and 1962. At that time a conservative treatment policy was in force and thus very few had surgical treatment in the first weeks of life. Although this group may be unrepresentative of today's survivors, this series is as close as is possible to the natural history of the condition.

\section{Materials AND Methods}

The 57 survivors included 32 cases of myelocele, 16 cases of meningocele, and 9 of encephalocele. The myelocele cases had a mean IQ of 89 and covered the whole spectrum of disability from being bedridden to complete independence, though as a group they had severe difficulties in locomotion. The meningoceles were generally free from physical handicap and had a mean IQ of 94, while the encephaloceles who often had sensory defects and mental retardation had a mean IQ of 52 . A detailed description of the population is reported elsewhere (Laurence and Tew, 1971). At the time of the enquiry the mean age of the spina bifida population was 11 years 7 months, with a range from 9 years 3 months to 15 years 8 months. Four families were from social classes I and II, 31 were from social classes III and IV, and 19 from social class $\mathrm{V}$; in three further instances the mother was unmarried, and the family could not be assigned to a social class. No control population was available. While the child was being given a battery of psychological tests, the parents completed a questionnaire, a part of which included the 'malaise inventory' (see Appendix) consisting of 24 questions which referred either to emotional states: 'Do you often feel miserable and depressed?' or to physical states known to have important psychological components: 'Do you feel tired most of the time?'. For each question the respondent was required to circle 'yes' or 'no'. The inventory was based on the Cornell Medical Index (CMI) (Brodman et al., 1949), 14 questions on the inventory being taken directly from the Index. 


\section{RESULTS}

Only the findings of 51 mothers are reported as the six questionnaires completed by the fathers was too small a number for valid comparisons to be made between the parents.

\section{SEVERITY OF HANDICAP}

The mother's malaise scores for the three diagnostic groups revealed distinct differences between the three types of lesion, encephaloceles having the highest mean scores and meningoceles the lowest scores (Table I). In view of the wide variation in disability within the clinical groups the subjects were classified into three broad categories of handicap on physical grounds only (Table II). The 'mild' category consisted of children with unaided ambulation who were totally continent. The 'moderate' group consisted of those who were ambulant only with the use of aids, and who were only partially continent or who achieved continence by means of surgical procedures. The 'severe' cases were generally chairbound or bedridden, totally incontinent, and often had severe sensory defects.

No appreciable difference was found between the mildly and moderately handicapped groups, but the scores obtained by mothers of the severely handicapped group were significantly higher than the scores obtained by mothers of moderately handicapped children. It is probably more meaningful

TABLE I

MOTHER'S MALAISE SCORE ACCORDING TO CHILD'S LESION

\begin{tabular}{lll|c|c|c}
\hline & & & \multicolumn{2}{c}{ Score } \\
\cline { 4 - 5 } Lesion & & Number & Mean & SD \\
\hline Meningocele & $\ldots$ & $\ldots$ & 15 & $4 \cdot 47$ & $3 \cdot 25$ \\
Myelocele & $\ldots$ & $\ldots$ & 28 & 6.93 & $5 \cdot 27$ \\
Encephalocele &.. & $\ldots$ & 8 & $9 \cdot 13$ & $6 \cdot 47$ \\
\hline
\end{tabular}

TABLE II

MOTHER'S MALAISE SCORE ACCORDING TO SEVERITY OF CHILD'S HANDICAP

\begin{tabular}{lll|c|c|c}
\hline \multirow{2}{*}{ Handicap } & & \multirow{2}{*}{ Number } & \multicolumn{2}{c}{ Score } \\
\cline { 5 - 6 } & & & Mean & SD \\
\hline Mild .. & $\ldots$ & $\ldots$ & 19 & 5.68 & 4.44 \\
Moderate & $\ldots$ & $\ldots$ & 17 & 5.18 & 3.57 \\
Severe & $\ldots$ & $\ldots$ & 15 & 9.20 & 6.71 \\
\hline
\end{tabular}

Mild $v$ severe $t=1 \cdot 75, P=0.10$ Moderate $v$ severe $t=2.08, \mathrm{P}<0.05$ to separate the population according to mobility. Division into those children who were mobile whether with or without aids and those who were immobile, permanently chairbound or bedridden revealed a significant difference in the malaise scores, the mothers of the mobile children having a mean score of $5 \cdot 15$ (SD $4 \cdot 13$ ) and those of the immobile having a mean score of $9 \cdot 11$ (SD 6.00) $(t=2 \cdot 49, \mathrm{P}=0 \cdot 2)$.

\section{INCONTINENCE}

A large proportion of children with a myelocele had paraplegia and associated neurogenic bladders. The population was divided into two groupsthose who were normally continent, and a slightly larger group who were wholly incontinent of urine $\stackrel{?}{?}$ and often of faeces, or who had a urinary diversion (Table III). The incontinent group included 12

TABLE III

MOTHER'S MALAISE SCORE ACCORDING TO CHILD'S URINARY STATUS

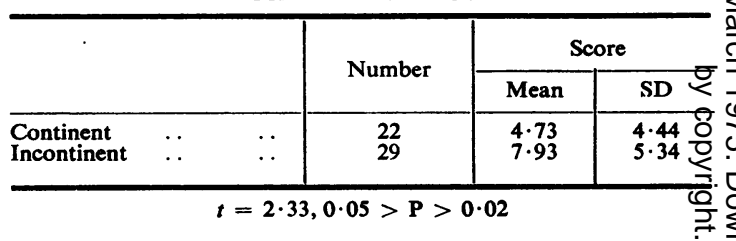

patients ( 7 girls and 5 boys) who had a urinary diversion operation. The malaise scores of the

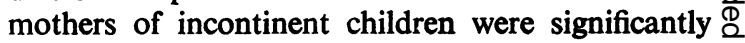
higher than the scores of the mothers of continent $\overrightarrow{\vec{A}}$ children. The scores of the mothers of girls with $\frac{5}{3}$ urinary diversion were the highest inthis study with $\supsetneq$ a mean score of 11.00 (SD 5.69) as compared with that of mothers of diverted boys-mean score $5 \cdot 20$ (sD 4.55).

\section{SCHOOLING}

A significant difference emerged between the mothers of children attending normal schools and those with children attending special schools, which 은 in 12 of the 15 cases involved residential facilities (Table IV), showing that the mothers of children attending special schools had higher malaise scores.

TABle IV

MOTHER'S MALAISE SCORE ACCORDING TO CHILD'S N
No
N్

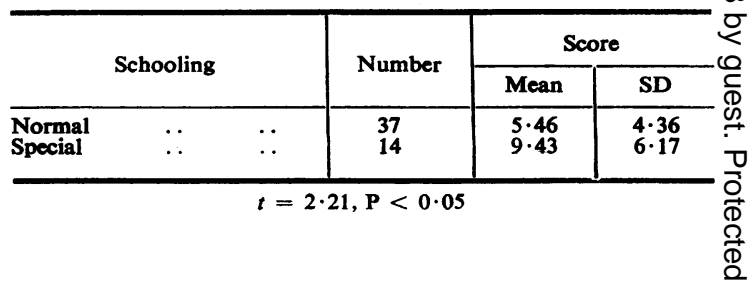




\section{INTELLIGENCE}

Separation into children likely to be competitive (IQ $80+$ ) and those likely to be non-competitive $(I Q<80)$ showed that mothers of non-competitive children had significantly higher stress scores (Table V). Most of the non-competitive children had clinical evidence of hydrocephalus, which often results in brain damage and associated disorders of learning and behaviour.

TABLE V

MOTHER'S MALAISE SCORE ACCORDING TO CHILD'S INTELLIGENCE

\begin{tabular}{ccc|c|c|c}
\hline \multicolumn{3}{c}{ IQ } & & \multirow{2}{*}{ Number } & \multicolumn{2}{c}{ Score } \\
\cline { 4 - 6 } & & & Mean & SD \\
\hline \multirow{2}{*}{$<80$} &. &. & 19 & 9.16 & 5.59 \\
$80+$ & $\ldots$ &.. & 32 & 5.00 & 4.30 \\
\hline
\end{tabular}

$t=2 \cdot 79, \mathrm{P}<0.01$

\section{Discussion}

A detailed comparison (Laurence, 1974) between the present population and a similar, though younger population, which was vigorously treated, revealed that the latter group were more disabled, both mentally and physically, than the largely untreated group we now report on. This suggests that our figures may underestimate the degree of stress found among parents of children now in primary schools.

In the absence of any psychiatric investigation of the parents of handicapped children, we had to rely on questionnaire data such as the 'malaise inventory' on the grounds that several studies have shown that the Cornell score agrees fairly well with independent psychiatric assessment. The inventory was found to be highly reliable. Rutter, Tizard, and Whitmore (1970) found that mothers of children having psychiatric disorder had significantly higher scores than mothers of children with physical disorders. The scores obtained in this study were in keeping with the scores obtained by mothers of children with psychiatric problems on the Isle of Wight.

In some respects the findings of this study support the commonsense observation that parental stress is at its highest when the child is severely handicapped. This was confirmed by Hare and his co-workers (1972) who found that $\mathrm{N}$ scores on the Maudsley Personality Inventory increased in relation to the duration of stress in mothers of spina bifida children. However, this study showed that the relationship was not linear, as there was little difference in response among mothers of children with a very slight handicap and of those who were moderately handicapped.

Although girls with spina bifida tend to be more severely handicapped, both mentally and physically, than boys (Laurence and Tew, 1971; Tew and Laurence, 1972), this did not seem to influence the malaise scores of the mothers (mothers of boys, $6 \cdot 43$ (SD 4.80); mothers of girls, $6 \cdot 70$ (SD 5.71)). Where there was more than one child in the family the malaise scores were no higher than in families with an only child. Mothers aged more than 35 at the time of the interview had slightly, but not significantly, higher scores than mothers under 35 .

Incontinence in spina bifida children appeared to be a most stressful condition for the mothers. This is probably because the mother is required to give close personal care and attention to her child at a time when he is ordinarily independent in his personal needs. The often embarrassing fact of urinary incontinence in an adolescent can create confusion in expectations, for incontinence is associated with infancy and dependency, which cannot easily be reconciled with advancing age. Further, incontinence may raise considerable fear and anxieties about the outcome, particularly as regards marital and sexual prospects, in adulthood. At present urinary diversion procedures have fallen into disfavour in some centres for purely medical reasons. Although the number of diverted cases in this study is small, there was some evidence that surgical interference of the genito-urinary system appears to have an emotional effect on the mothers of girls so treated.

The finding that mothers of children attending residential schools had significantly higher stress scores than mothers of children attending normal schools requires interpretation. Pupils in special schools tend to be more severely handicapped physically, mentally, and often socially than those attending normal schools. It seems that a decision to admit a child to a residential school is often made on social grounds, probably based on the assumption that when the child is away at school the mother, in particular, may be relieved of the day to day care of her child, which can be very taxing, and the normal siblings can be given their fair share of attention. The care of the child can be at the expense of the mother's health (Tew and Laurence, 1973); the life of both parents may be circumscribed by caring for a crippled, highly dependent child and they can be thrown upon each other's resources to a much greater degree than would be usual in a family with a normal child (Tew, 1974). This can lead to considerable matrimonial discord and a 
divorce rate more than twice that found among matched controls (Tew, Payne, and Laurence, 1974). Whether residential educational facilities for the child produce a change in the mother's emotional state cannot be answered from this study.

We wish to thank Dr. E. H. Hare for his helpful criticism and Mr. P. Samuel for assistance with the computing. The financial assistance of the Mental Health Research Fund, Joint Clinical Research Fund, Welsh Hospital Board, the Nuffield Provincial Hospitals Trust, the Catherine and Lady Grace James Foundation, and Tenovus is gratefully acknowledged.

\section{REFERENCES}

Brodman, K., Erdmann, A. J., Lorge, I., WolfF, H. G., and Broadbent, T. H. (1949). The Cornell Medical Index. An adjunct to medical interview. J. Amer. med. Ass., 140, 530.

D'ARCY, E. (1968). Congenital defects: mother's reactions to first information. Brit. med. J., 3, 796.

FreEston, B. M. (1971). An enquiry into the effect of a spina bifida child upon family life. Develop. Med. Child Neurol., 13, 456.

hare, E. H., Laurence, K. M., Payne, H., and RAWNSLEY, K. (1966). Spina bifida cystica and family stress. Brit. med. J., 2, 757.

- Payne, H., LauRence, K. M., and Rawnsley, K. (1972). Effect of severe stress on the Maudsley Personality Inventory Score in normal subjects. Brit. J. Soc. clin. Psychol., 11, 353.

HUNT, G. M. (1973). Implications of the treatment of myelomeningocele for the child and his family. Lancet, 2, 1308.
LAURENCE, K. M. (1974). Effect of early surgery fof spina bifida cystica on survival and quality of life Lancet, 1, 301.

and TEw, B. J. (1971). The natural history of spin bifida cystica and cranium bifidum cysticum. The major central nervous system malformations in Soutb Wales, Part IV. Arch. Dis. Childh., 46, 128.

Richards, I. D. G. and McINTosh, H. T. (1973). Spin bifida survivors and their parents: A study of problems and services. Develop. Med. Child Neurol., 15, 2930

RUTTER, M., Tizard, J., and WhITMORE, K. (1970). Education, Health and Behaviour. Longmans, London.

Tew, B. J. (1974). Spina bifida: family and sociat problems. Special Education: Forward Trends, 1, 1 R.

- and LAURENCE, K. M. (1972). The ability an\$ attainments of spina bifida patients born in South Wales between 1956 and 1962. Develop. Med. Chik Neurol., 14 Suppl. 27, 124.

- and - (1973). Mothers, brothers and sisters of patients with spina bifida. Develop. Med. Chito Neurol., 15, Suppl. 29, 69.

- , Payne, H., and Laurence, K. M., (1974). Mus a family with a handicapped child be a hand capped family? Develop. Med. Child Neurol., 16, SuppP. 32,95 .

WalKer, J. M., Thomas, M., and Russell, I. T. (1998) Spina bifida and the parents. Develop. Med. CFild Neurol., 13, 462.

Requests for reprints to: Dr. K. M. Laurence, Chilg Health Laboratories, Department of Child Health, Heat $\frac{1}{8}$ Park, Cardiff CF4 4XN.

APPENDIX

Health Questionnaire

MALAISE INVENTORY GIVEN TO MOTHERS

Please ring the correct answer

1 Do you often have backache?

2 Do you feel tired most of the time?

3 Do you often feel miserable or depressed?

4 Do you often have bad headaches?

5 Do you often get worried about things? ..

6 Do you usually have great difficulty in falling asleep or staying asleep?

7 Do you usually wake unnecessarily early in the morning? .

8 Do you wear yourself out worrying about your health? ..

9 Do you often get into a violent rage?

10 Do people often annoy and irritate you?

11 Have you at times had a twitching of the face, head or shoulders?

12 Do you often suddenly become scared for no good reason?

13 Are you scared to be alone when there are no friends near you?

14 Are you easily upset or irritated?

15 Are you frightened of going out alone or of meeting people?

Are you constantly keyed up and jittery?

17 Do you suffer from indigestion?

18 Do you often suffer from an upset stomach?

19 Is your appetite poor?

20 Does every little thing get on your nerves and wear you out?

21 Does your heart often race like mad?

22 Do you often have bad pains in your eyes?

Are you troubled with rheumatism or fibro

Have you ever had a nervous breakdown?

..

$\cdot$

..

.

..

.
. Yes

.. Yes

. Yes

.. Yes

.. Yes

.. Yes

.. Yes

.. Yes

.. Yes

.. Yes

.. Yes

.. Yes

.. Yes

.. Yes

.. Yes

.. Yes

.. Yes

.. Yes

.. Yes

.. Yes

.. Yes

.. Yes

.. Yes

.. Yes
No

No

No

No

No

No

No

No

No

No

No

No

No

No

No

No

No

No

No

No

No

No

No

No 